\title{
Research Into The New Model Of College ENGLish TEACHING-A MULTIMOdALITY APPROACH
}

\author{
Qian Wang \\ School of Foreign Languages of Northwestern Polytechnical University \\ Xi' an, Shaanxi, China
}

\begin{abstract}
Currently, the application of the network resources and various means of teaching such as multimedia into the classroom has led to the demonstration of multimodality in college English teaching. This paper analyzes the current status of college English teaching and the existing problems, elaborates the research trends of the theory of multimodal discourse analysis, and aims to explore the question as how to construct college English teaching model from the perspective of multimodal discourse. Under the multimodalitybased college English teaching model, teachers should concentrate on cultivating students' multi-literacy, coordinating different modalities, to achieve the teaching objectives.
\end{abstract}

\section{KEYWORDS}

Multimodal Discourse, College English teaching, Multi-literacy, Teaching model

\section{INTRODUCTION}

Over the last few decades, the world we live in has witnessed significant changes both in the way of communication and in the approach to teaching and learning at colleges, due to the development of information and communication technologies. Currently, college English teaching in China uses a teaching mode combining independent study with computer and multimedia classroom teaching supported by network technology. The constantly increased media in the classroom makes education present a multimodality trend. The popularization of multimedia technology and network technology injects vitality into the reform of English classroom situational teaching. Information transfer mode is no longer confined to a single text. Instead, it includes multiple modes such as audio frequency, video and three-dimensional animation. These modern means enrich semantic expression forms, break the oneness of conventional media and reflects fixed multimodality nature of communication. The ultimate goal of language teaching is to allow learners to know how to use a language for communication in a correct language environment, put them in a certain language environment and allow them to comprehend, practice and use language.

In China, the domestic Scholar Zhang Delu[1] focused on discussing the use of system-functional linguistic theory to provide theoretical framework for multimodality discourse analysis and research and providing guidance on selection of effective teaching process and practice for foreign language teaching practice under the condition of modern media technology. This also provides possibility for the establishment of college English teaching mode based on multimodality discourse analysis theory. New College English Course Teaching Requirements requires colleges and universities to make full use of multimedia and network technologies, DOI :10.5121/ijite.2015.4304 
International Journal on Integrating Technology in Education (IJITE) Vol.4, No.3,September 2015

together with a new teaching mode to improve the traditional classroom teaching mode mainly involving teachers' instruction. The establishment of multimodality college English classroom teaching mode is conducive to training students' diversified literacy and abilities of listening and speaking and can effectively realize mutual coordination of different modes and jointly achieve the goal of college English teaching.

\section{Theoretical Basis ANd Exploration Of Multimodality College ENGLish TeACHING Mode}

\subsection{Concept and Research Status of Multimodality Discourse}

Modality is the abstract language symbol system. Media is the physical device of symbol distribution and physical tool of expressing information. Media makes the abstract modality concrete. For example, visions, hearing, touching, smelling and tasting are five modalities, while eyes, ears, hands, noses and tongues are media. The application of each modality is realized through the corresponding medium. Multimodality is also called as multi-symbol, including spoken language, written language, image, diagram, space and various kinds of symbol resources used to construct meanings. The application of multimodality is a phenomenon of communication through many kinds of devices and symbol resources. Multimodality is one of the characteristics of the different discourses in modern society. In the digital information era, these different modalities function similarly in the level of meaning recurrence.

Multimodality discourse analysis is a new discourse analysis method based on system-functional linguistic theory emerging in 1990s. This theory puts forward that such symbols as images, colors and actions considered as paralanguage in traditional habits are no longer in an auxiliary position in modern social communication but are forming a broader symbolic resource with letter symbol to jointly participate in meaning construction based on functional grammar of Halliday mainly from the perspective of social semiotics. Chinese system-functional grammar expert Professor Hu Zhuanglin [13] has conducted in-depth research on multimodality and translated it into “多模态化” in Chinese. Zhu Yongsheng [11] considered that modality is a communication channel and medium, including such symbol systems as language, technology, image, color and music, and discourses involving two or more modalities are "multimodality discourse". Zhang Delu[1] considered that multimodality discourse refers to the phenomenon of communication through multiple means and symbolic resources such as language, image, voice and action by using multiple senses such as auditory sense, visual sense and tactile sense. The author thinks that multimodality discourse refers to texts involving multiple perception modalities or having common coding of more than one symbol systems to establish the whole meaning and convey the information. Multimodality teaching can be understood as the way that teachers (or students) fully use multimodalities in multimedia environment such as video, film editing, recording, picture, chart, material object and prop to obtain, transmit and receive information.

In recent decade, the analysis and application of multimodality in teaching is one of the hot topics in America and Europe. R. Barthes, one of the earliest researchers in multimodality, issued the paper Rhetoric of the Image in 1977, during which he explored the interaction between the expression of image and language. New London Group [7] was the first applying multimodality to language teaching. They thought the training of the students' multi-literacy was the main task of language teaching. From then on, the researches concerning multimodality and language teaching began to prevail. Kress, G.\& van Leeuwen, T. [5] studied the relationship between modality and media, and put forward the schemes and application principles of training multiliteracy under the setting of multimodality. Royce, T. [10] researched the complementary of different symbols in multimodal discourse and the collaboration of multimodality in second 
language teaching. Guichon \& McLornan [3] probed into the effects of multimodality on second language learners, and put forward the designation principles and ways of the curriculums of computer assisted teaching. Many scholars pay attention to the study of PPT demonstration in class. Fisher [2] posed some questions of the application of PPT in class. Nouri \& Shahidy [9] made an empirical study and explored the relativity between the students' attitudes and memorization when teaching the knowledge of theories. Compared with what has been achieved in the West, the study of multimodal discourse in China is at its infancy. The earliest study concerning relationship between multimodality and foreign language teaching are Gu Yueguo and $\mathrm{Hu}$ Zhuanglin. Gu Yueguo [12] distinguished between the two concepts of multimedia study and multimodality study, and constructed a model used to analyze the two kinds of studies. $\mathrm{Hu}$ Zhuanglin[13] discussed the differences between multimodality semiotics and multimedia semiotics, and introduced computer semiotics with double characteristics of media and modality. Li Zhanzi [14] studied multimodal discourse theory by using the linguistic theory of systematic function. Zhu Yongsheng [11] explored the implications of multimodality to teaching reform in China. Zhang Delu[1] established a comprehensive frame for the analysis of multimodal discourse. He pointed out that the study of multimodality in China was at its initial stage, and especially there were fewer researches on the most frequently used PPT in class. PPT, as a form of multimodality, plays an important role in foreign language teaching and Chinese students' English learning. The study of PPT can support the theory and practice of foreign language teaching in China, and accelerate the process of foreign language teaching reform, enrich the theories of multimodal discourse analysis.

\subsection{Theoretical Basis and Exploration of Multimodality College English Teaching Mode}

From what has been discussed, multimodality discourse theory could work well for establishing Multimodality college English teaching practice. Modern college English class has widely used PPT software for multimedia teaching. The use of multimodality discourse theory has provided scientific methods for rational analysis on classroom teaching quality. In this paper, the comprehensive framework of multimodality discourse analysis of Martin [8] and Zhang Delu [1] is adopted as the theoretical basis of multimodality college English teaching mode. Zhu Yongsheng [11] and Zhang Delu [1] described in detail that system-functional linguistic theory has opened new perspectives for multimodality discourse research. According to the research of Martin [8] on multimodality discourse, the theoretical framework of multimodality discourse analysis is mainly composed of basic factors and conditions of system and selection at five levels, i.e. culture, context, meaning, form and media (see table 1).

Table 1. Theoretical Framework of Multimodality Discourse Analysis (Martin, 1992)

\begin{tabular}{|c|c|c|}
\hline \multirow{5}{*}{$\begin{array}{l}\text { Theoretical } \\
\text { framework } \\
\text { of } \\
\text { multimodality } \\
\text { discourse } \\
\text { analysis }\end{array}$} & $\begin{array}{l}\text { Cultural } \\
\text { level }\end{array}$ & Ideology and types \\
\hline & $\begin{array}{l}\text { Context } \\
\text { level }\end{array}$ & Scope, tenor and mode of discourse \\
\hline & $\begin{array}{l}\text { Meaning } \\
\text { level }\end{array}$ & $\begin{array}{l}\text { Discourse meaning, conceptual meaning, } \\
\text { interpersonal meaning and textual meaning }\end{array}$ \\
\hline & \begin{tabular}{l|} 
Form \\
level
\end{tabular} & $\begin{array}{l}\text { Different formal systems of meaning, lexical } \\
\text { grammatical system of language, visual } \\
\text { ideographic object and grammatical system, } \\
\text { auditory ideographic sound block and } \\
\text { grammatical system, ideographic object and } \\
\text { tactile grammatical system and relationship } \\
\text { of grammar of each modality }\end{array}$ \\
\hline & $\begin{array}{l}\text { Media } \\
\text { level }\end{array}$ & $\begin{array}{l}\text { Facial expression, gesture, body gesture and } \\
\text { action; PPT, laboratory, network platform, } \\
\text { material object(projection), sound and } \\
\text { simultaneous interpretation room etc. }\end{array}$ \\
\hline
\end{tabular}


Zhang Delu[1] conducted a systematic research on multimodality discourse analysis according to Halliday's system-functional linguistic theory and put forward the theoretical framework of comprehensive analysis on multimodality discourse (see fig.1). According to the figure, this framework is divided into four levels: culture, context, content and expression. Content level integrates meaning and form levels of theoretical framework of multimodality discourse analysis put forward by Martin [8] and highlights correlation of formal characteristics of different modalities. It's worth noting that each level of the comprehensive framework of multimodality discourse analysis has coordinated, correlated and complementary relations. Currently, multimodality discourse research still focuses on formal characteristics of different modalities and their relation. This paper attempts to establish multimodality college English teaching mode according to the comprehensive framework of multimodality discourse analysis of Martin [8] and Zhang Delu [1], discusses how to realize mutual coordination and harmonic unification of teachers and students in college English classroom and culture, situation, content and expression levels, effectively train students' diversified literacy and abilities of listening and speaking and jointly improve teaching efficiency.

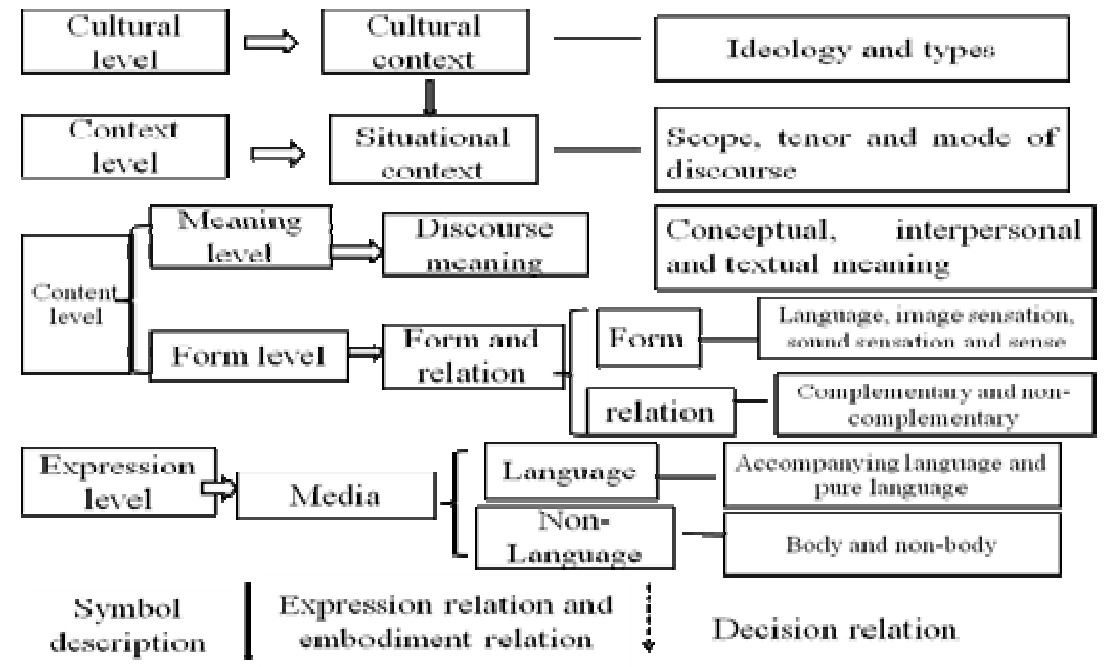

Fig. 1. Comprehensive framework of multimodality discourse analysis (Zhang Delu, 2009)

\section{Establish Multimodality College English Teaching Mode}

\subsection{Concept of Multimodality College English Teaching Mode}

Multimodality college English teaching means that teachers start from the perspective of multimodality discourse analysis, fully understand students' cognitive psychology and their role in class, select teaching situation in the form of face to face teaching in class and students' selfstudy guidance, construct meaning with the help of multimodality symbolic resources, appropriately handle the coordination of multiple modalities at culture, situation, content and expression levels, integrate their speech, posture and multimodality classroom teaching environment presented by multimedia and finally realize harmony among teachers, students and multimedia in college English classroom under the guidance of comprehensive framework of multimodality discourse analysis of Martin[8] and Zhang Delu [1] according to the situation of multimodality trend presented in teaching classroom. Teachers should focus on training students' diversified literacy and ability of comprehensive language application, pay attention to mutual coordination of different modalities and complementation of different teaching means in the process of teaching practice and jointly improve the quality of college English teaching. 
International Journal on Integrating Technology in Education (IJITE) Vol.4, No.3,September 2015

\subsection{Requirements of Multimodality College English Teaching Mode}

In Curriculum Requirements issued by Chinese Ministry of Education in 2009, it is pointed out that as a systematic whole, College English takes as its main components knowledge and practical skills of the English language, learning strategies and intercultural communication; it takes theories of foreign language teaching as its guidance and incorporates different teaching models and approaches. The objective of College English is to develop students' ability to use English in an all-round way, especially in listening and speaking, so that in their future work and social interactions they will be able to exchange information effectively through both spoken and written channels, and at the same time they will be able to enhance their ability to study independently and improve their cultural quality so as to meet the needs of China's social development and international exchanges.

In order to achieve the objective, we should make use of the technology of multimedia and network, adopt the new teaching model of multimodality, and improve the previous monomodality teaching model in which the teaching dominates. The multimedia network offers large amount of language learning materials for teachers and students. The choice of multimodality provides different kinds of expressions for communication, deepens understanding and memorizing.

In the teaching process, teachers should select the meaning to be expressed according to specific situational context, including conceptual, interpersonal and textual meanings and help students to construct language discourse ability. To express appropriate meaning, teachers should learn to select the use of each expression level of multiple modalities. In college English teaching, teachers should appropriately use the complementary relationship among discourse scope (fields involved in the teaching content), discourse tenor (state of teaching objects and relationship between teaching objects and instructor) and discourse mode (teaching conditions and site etc.) at the situation level of multiple modalities, because multimodality college English teaching mode involves the coordination of internal media of modalities. In teaching reading and writing, teachers generally use the method of explanation, explain the meaning of discourse clearly and then use living examples for further explanation. Forms of media include book, PPT, oral teaching and question answering, etc. Modalities involved are visual sense (book and PPT) and auditory sense (oral teaching and question answering). For example, in the explanation of words in English teaching, the meaning of words in context can help students make clear the use method of this vocabulary. In listening and speaking teaching, teachers should make full use of resources provided by multiple modalities at culture, content and expression levels, put real communicative context in class and use images, video and sound provided by auditory sense and visual sense modalities as the actual learning environment, teaching form combining language and non-language use and role play to improve students' ability of using communicative strategies in a real context.

In multimodality college English teaching mode, classroom effect depends on the coordination of internal media of modalities to a great extent. Language and image modalities are two favorable methods of teachers and students for constructing meaning. Giving a lesson is the coordination of visual sense modality and auditory sense modality. In multimodality discourse theory, language, auditory sense, visual sense and tactile sense are social symbols with their own meaning potential. They should be important modalities for constructing meaning. Teachers should guide students to use multimedia network resources to realize their understanding of knowledge and construction of meaning and meanwhile improve their mastery of language knowledge and ability of constructing language discourse. Teachers should appropriately use PPT resources and multimodality symbols to provide teaching situation, convenience and supplementary conditions for foreign language teaching in situational context in class so as to improve teaching efficiency. 
For PPT resources wisely used under multimedia, Hu Zhuanglin [13] divided various discourses of PPT categories into four types: prompt type, intuitive type, analysis type and persuasion type and divided modalities used in PPT discourse into visual sense modality and auditory sense modality. Multimodality college English mode requires the use of multiple modalities in class to enrich the classroom content. Background music can rapidly color the atmosphere; images can intuitively attract the attention of students; text explanation can help students understand the knowledge content. Teachers' body language and infectious explanations accompanied can improve teaching quality. Hu Zhuanglin [13] also considered, "traditional literacy mainly focusing on reading and writing is not enough in multimedia era". Today, with the integration, diversification and technicalization of the current world, it is not only required to train students' reading and writing abilities. More importantly, it is required to train their diversified literacy.

For example, the goal of integrated course is to pass on knowledge, introducing culture and training language skills. Teachers will explain the content intensively, and students will do large amount of exercises to consolidate or digest what they are supposed to command. Usually, students are the center of the class and the main media ways are textbooks, multimedia courseware, teachers' teaching activities, students' question-answering activities, so the main form of modalities are vision and hearing. This kind of teaching pattern involves the collaboration between media inside the modality. Courseware shows the important information by using the vivid pictures and the different typefaces. Textbooks act as the supplement by providing the specific information. In the process of teaching, teachers will raise some questions for students to answer. The application of hearing modality needs vision to cooperate. Teachers can judge whether students understand the materials they are studying according to the students' reaction. Therefore, in this kind of teaching model, over two modalities are applied, which accelerates the conveyance of information, and changes the previous unitary teacher-centered pattern of language teaching with the help of multimedia. The new teaching pattern is free from the constraints of the time and places, which embodies the central role of students and the interaction of learning.

One teaching case could be raised to illustrate the importance of multimodal discourse employed in class. In the Text A, Book One of twenty-first century College English, the topic is Conversational Ballgames. In class, the teacher explains the different ballgames by demonstrating some pictures and background information via PPT, and compares them to Japanese-style conversation and English-style conversation. By discussing the different rules of the ballgames, the teacher elaborates the different language styles under the different cultural backgrounds and how the differences lead to a series of interesting results in the interaction between people. Through the demonstration of PPT, the students learn different styles and rules of conversation. Then the teacher divides the students into some group and asks them to discuss the different conversation styles and summarize the corresponding conversational rules and characteristics. After that, the teacher plays a piece of video in which an actress acts as people from different countries speaking different styles of English. The actress speaks with obvious characteristics of different countries and the students can identify the different styles easily. They are American, African, Chinese and Indian. Finally, the teacher poses a question: besides language, what other factors cause to form the conversational style? With the help of the previous video, the students list a series of factors, such as facial expression, body language, way of thinking, clothes and so on. Through the discussion and guidance above, the students understand that language reflects culture, so learning a language, one must learn the culture. Students should develop a right attitude toward language learning. In the process of learning, the students have a good command of this unit under the setting of multimodality. 
International Journal on Integrating Technology in Education (IJITE) Vol.4, No.3,September 2015

\section{CONCLUSIONS}

This paper attempts to establish multimodality college English teaching mode based on the comprehensive framework of multimodality discourse analysis of Martin (1992) and Zhang Delu (2009). The research finds that the meaning of multimodality college English teaching mode is that it can integrate language and other relevant meaning resources. We can see not only the role of language system in the meaning exchange process, but also the effect of other symbol systems such as auditory sense, visual sense, picture and tactile sense modalities in this process, thus making the interpretation of discourse meaning more comprehensive and accurate and providing convenience for the realization of teaching situations in foreign language teaching. Research also finds that multimodality college English teaching can allow teachers and students to obtain information through multiple channels and jointly construct the meaning to be expressed by teachers and the meaning to be mastered by students and is conducive to obtaining the optimal effect of teaching. On one hand, multimodal discourse analysis offers a new perspective for college English teaching. On the other hand, it supplies a solution for some teaching problems. Multimodal discourse analysis enriches the theoretical framework of college English teaching, optimizes the college English teaching system and helps students develop individual sustainability. Teachers combine it with the one's own personality by integrating some suitable modes to better facilitate the teaching process and during the teaching process. The establishment of multimodality college English teaching mode cannot be accomplished in an action. It should be tested and improved constantly in the practice of college English teaching.

Besides, We have to be fully aware that though the new network environment provides students with wider space of study and communication in the course of transformation from single modality to double modality and even to multimodality, through which they will exchange their feelings, ideas, interests and hobbies in the setting of the network, students' autonomous learning becomes more complicated in this kind of environment, so it becomes more difficult to monitor their autonomous learning process effectively. With the complexity of the multimodality setting, the diversification of the interactive modality, the socialization of the students' communication, the learning process of the students must be guided and monitored properly with better improved monitoring model. Therefore, this research aims at throwing a sprat, from which college English teaching practice could be more inspired. Undoubtedly, it needs more researches to guide the learners to study independently under the setting of multimodality.

\section{ACKNOWLEDGEMENTS}

This study is supported by the Fundamental Research Funds for the Central Universities under grant No. 3102014RW0023 and Higher Education Research Fund under grant No. 2014GJY09

\section{REFERENCES}

[1] Delu, Zhang, On a Synthetic Theoretical Framework for Multimodal Discourse Analysis, Foreign Languages in China (1), PP. 24-30, 2009.

[2] Fisher, D. L. Using PowerPoint for ESL teaching, The Internet TESL Journal. Vol. IX, 2003.

[3] Guichon, N. \& S. McLornan, The effects of multimodality on L2 learners: Implications for CALL resource design, System, 36, 2008.

[4] Kress, G. \&Van Leeuwen, T. Reading Images: The Grammar of Visual Design, London: Routledge, 1996.

[5] Kress, G. \& Van Leeuwen, T. Multimodal Discourse: The Modes and Media of Contemporary Communication, London: Arnold, 2001.

[7] New London Group, A pedagogy of multiliteracies: Designing social futures, Harvard Educational 
Review, 66(1), PP. 60-90, 1996.

[8] Martin, J.R. English test: System and Structure, Amsterdam: John Benjamins, 1992

[9] Nouri, H. \& A. Shahidy, The effect of Power Point presentations on student learning and attitudes, Global Perspectives on Accounting Education, Vol. 2, (1), 2005.

[10] Royce, T. Multimodality in the TESOL classroom: Exploring visual-verbal synergy, TESOL QUARTERLY, 36(2). PP. 191-205, 2002.

[11] Yongsheng, Zhu, The research on Multiliteracy and its implications to the teaching reforms in China, Foreign Languages Research (4), PP. 10-14, 2008.

[12] Yueguo, Gu, Analysis of Multimedia and Multimodality, Computer-assisted Foreign Language Teaching (2), PP. 3-12, 2007.

[13]Zhuanglin, Hu, Multimodalization in Social Semiotics, Language Teaching and Linguistic Studies (1), PP. 1-10, 2007.

[14] Zhanzi, Li, Social Semiotics Analysis of Multimodal Discourse, Foreign Languages Research (5), 2003.

\section{Author}

Qian Wang(1981-), MA., Assistant Professor in School of Foreign Lan guages of Northwestern Polytechnical University in China.

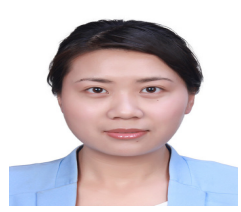

